\title{
FLUCONAZOLE PLASMA CONCENTRATION MEASUREMENT BY LIQUID CHROMATOGRAPHY FOR DRUG MONITORING OF BURN PATIENTS
}

\author{
doi: $10.1590 / \mathbf{S 1 8 0 7 - 5 9 3 2 2 0 1 0 0 0 0 2 0 0 0 1 7}$
}

Silvia Regina Cavani Jorge Santos, ${ }^{\mathrm{I}}$ Edvaldo Vieira Campos, ${ }^{\mathrm{II}}$ Cristina Sanches, ${ }_{\mathrm{I}}$ David Souza Gomez, ${ }^{\mathrm{III}}$ Marcus Castro Ferreira ${ }^{\mathrm{III}}$

\section{INTRODUCTION}

Fluconazole (2-(2,4-difluorophenyl)-1,3-bis(1H-1,2,4triazol-1-yl)-2-propanol) is a triazole antifungal agent that has been available since 1990. Fluconazole is a broadspectrum triazole antifungal agent that has emerged as a suitable alternative to amphotericin B in the treatment of a wide variety of superficial and systemic fungal infections. ${ }^{1}$ Triazole drugs act by inhibiting the enzyme 14- $\alpha$-demethylase, which belongs to the microsomal CYP system; triazoles also act by blocking the biosynthesis of ergosterol, resulting in the accumulation of $14-\alpha$-methyl sterols and producing a fungistatic action. In general, fluconazole is well tolerated, with side effects including nausea, headache, skin rash, vomiting, abdominal pain, and diarrhea occurring during long-term therapy. ${ }^{2}$

Excellent bioavailability has been reported after oral dosing, and a linear pharmacokinetics has been demonstrated at a dose of 200-800 $\mathrm{mg}$ daily. The elimination half-life of fluconazole ranges from 27 to 37 hours, the apparent volume of distribution ranges from 0.5 to $0.7 \mathrm{~L} / \mathrm{kg}$, and approximately $80 \%$ of unchanged drug is excreted in the urine. $^{3-6}$

Fluconazole is now used prophylactically in the management of various immune-compromised patient subsets $^{1}$. High morbidity and mortality in patients with severe

\footnotetext{
I School of Pharmaceutical Sciences, Universidade de São Paulo - São Paulo/ SP, Brazil

II Servico de Terapia Intensiva, Hospital do Servidor Publico Estadual - São Paulo/SP, Brazil

III Plastic Surgery and Burns, Hospital das Clinicas da Faculdade de Medicina da Universidade de São Paulo - São Paulo/SP, Brazil

Email: pharther@usp.br

Tel.: 55113069.2189
}

thermal injury were associated with fungal sepsis; thus, a study of the efficacy of this drug to prevent fungal sepsis in burn patients is necessary. It is well-known that patients with thermal injuries show many changes in the pharmacokinetics of several drugs, but data on the clinical efficacy of fluconazole related to its kinetics are very limited. ${ }^{7,8}$ Since changes in the pharmacokinetics of fluconazole are still unknown, it is imperative to investigate burn patients' drug levels with a controlled clinical protocol.

Analytical methods using microbiological, spectrophotometric, and chromatographic techniques have all been shown to determine fluconazole in biological samples. High-performance liquid chromatography (HPLC) is preferred due to its selectivity and the specificity of the assay. Methods for the determination of fluconazole in biological samples by HPLC-UV have been described previously. ${ }^{9-16}$ The objective of the present study was to develop a simple analytical method to determine fluconazole for plasma drug monitoring in patients with extensive thermal injury. An additional focus is its application to future pharmacokinetic studies. The method was validated as per FDA guidelines. ${ }^{17}$

\section{MATERIALS AND METHODS}

\section{Experimental}

\section{Reagents and Chemicals}

Standards of fluconazole and carbamazepine (internal standard) were purchased from Sigma (St. Louis, MO, USA). All solvents (HPLC grade), reagents for drug extraction, and HPLC analysis ingredients were purchased from Merck (Darmstadt, Germany). Purified water was obtained from Millipore Simplicity System (Milford, MA, USA). 


\section{Instrumentation}

The chromatographic system consisted of a Shimadzu model LC-10AVP solvent delivery module (Kyoto, Japan) equipped with a CBM 101 controller/software Class VP, an autosampler (model SIL-10ADVP) and a detector (UV -VIS model SPD-10AVP). The peak areas were integrated using a Shimadzu CR6A integrator with printer/plotter. The analytical column was a Shimpack CN $(150 \times 6.0 \mathrm{~mm}, 5$ $\mu \mathrm{m}$ Shimadzu, Kyoto, Japan), with a Nova Pak C18 guard column (Waters Assoc., Milford, USA).

\section{Chromatographic Conditions}

The mobile phase was a mixture of purified water and acetonitrile $(60: 40 \mathrm{v} / \mathrm{v})$, freshly prepared on the day used and filtered through a 0.45- ( $\mu \mathrm{m}$ filter and helium degassed for 3 minutes. The chromatographic analysis was performed in an isocratic system using a flow rate of $0.5 \mathrm{~mL} \mathrm{~min}-1$ at room temperature. The injection volume was $5 \mu \mathrm{L}$, and the effluent was monitored by an ultraviolet absorbance detector at 210 $\mathrm{nm}$. A run time of 15 minutes was required to guarantee the selectivity of chromatographic analysis.

\section{Preparations of Standards and Internal Controls}

The stock fluconazole solution was prepared by dissolving the appropriate amount of fluconazole standard $(10 \mathrm{mg})$ in ultrapure water to reach a final drug concentration of $1.0 \mathrm{mg} \mathrm{mL} \mathrm{m}^{-1}$. Volumes of $5 \mathrm{~mL}$ of stock solution of fluconazole were transferred to a volumetric flask $(50 \mathrm{~mL})$. The higher standard $\left(100.0 \mu \mathrm{g} \mathrm{mL}^{-1}\right)$ was obtained by adding the stock solution to drug-free human plasma (blank). Linearity was investigated by dilution of the higher standard to obtain the following concentrations of fluconazole in plasma: 100.0, 50.0, 20.0, 10.0, 5.0, 2.0, 1.0, 0.4 and 0.2 $\mu \mathrm{g} \mathrm{mL}-1$; the calibration curve across the range $0.4-100.0$ $\mu \mathrm{g} \mathrm{mL^{-1 }}$ was constructed daily. Internal quality controls were prepared by dilution of the stock solution in drug-free plasma to obtain the following high $\left(90.0 \mu \mathrm{g} \mathrm{mL}^{-1}\right)$, medium $\left(50.0 \mu \mathrm{g} \mathrm{mL}^{-1}\right)$ and low $\left(1.2 \mu \mathrm{g} \mathrm{mL}^{-1}\right)$ concentrations. Aliquots of $0.5 \mathrm{~mL}$ from plasma standards and also from the internal controls were distributed into Eppendorf tubes and stored at $-20{ }^{\circ} \mathrm{C}$ until assayed.

A stock solution of carbamazepine, the internal standard (IS), was prepared in methanol at $1 \mathrm{mg} \mathrm{mL}^{-1}$; an intermediate solution was prepared by diluting the stock solution with methanol to reach the concentration $100 \mu \mathrm{g} \mathrm{mL} L^{-1}$. Finally, the solution of the IS was prepared freshly by diluting with methanol to reach $20 \mu \mathrm{g} \mathrm{mL}-1$. Fifty $\mu \mathrm{L}$ was then added per assay, and methanol was evaporated to dryness in a water bath before analyses.

\section{Sample Extraction Procedure}

Extraction tubes of IS $(50 \mu \mathrm{L})$ were added, and the methanol was evaporated. Next, tubes containing dried IS were added to plasma ( $200 \mu \mathrm{L}$ ) and $50 \mu \mathrm{L} 1.25 \mathrm{M}$ sodium hydroxide, and the mixture was vortexed for 10 seconds. Drug extraction was performed by adding $3 \mathrm{~mL}$ dichloromethane and vortexing for 1 minute, following by centrifugation at $3000 \mathrm{rpm}$ at $4^{\circ} \mathrm{C}$ for 30 minutes. The upper phase was aspirated and the tube containing the organic phase was immersed in a liquid nitrogen bath. The organic phase was then carefully transferred to a conic tube. Solvent was evaporated to dryness in a water bath under a nitrogen stream at $37^{\circ} \mathrm{C}$. Residue was dissolved with $200 \mu \mathrm{L}$ of a mixture of acetonitrile and ultrapure water $(8: 2 \mathrm{v} / \mathrm{v})$, and under the conditions above detailed, $5 \mu \mathrm{L}$ volumes were injected into the HPLC.

\section{Linearity, Calibration Curve and Calculation Proce- dures}

The nominal value of fluconazole in plasma was plotted as a function of the peak area ratio of the internal standard to the drug concentration. A linear regression line was made, and the estimated linear correlation coefficient was applied to the calibration curve. At least six calibrators were included in the construction of the daily calibration curve of $0.4-100.0 \mu \mathrm{g} \mathrm{mL}^{-1}$. The daily curve was accepted if at least $4 / 6$ of the internal controls (high, medium and low concentrations, analyzed in duplicate) presented systematic error lower than $15 \%$. At least one control of each concentration was within the acceptable variation. Once accepted, the calibration curve was applied to estimate drug concentration in samples from patients. The linearity of the method was determined in triplicate for each concentration ranging from 0.4 to $100.0 \mu \mathrm{g} \mathrm{mL}^{-1}$

\section{Accuracy, Precision and Recovery}

The precision of the quantitative method is the degree of agreement among individual tests when the procedure is applied repeatedly to multiple replicates of three different concentrations. Data were expressed as the coefficient of variation (CV\%). The intra-day precision was evaluated by analysis of three replicates of the high $(90.0$ $\left.\mu \mathrm{g} \mathrm{mL} L^{-1}\right)$, medium $\left(50.0 \mu \mathrm{gL}^{-1}\right)$ and low $\left(1.2 \mu \mathrm{gL}^{-1}\right)$ concentrations. The inter-day precision was determined by the analysis of three replicates of the high, medium and low concentrations of fluconazole on three different days $(n=27)$.

Accuracy was evaluated by analysis of multiple replicates of three different concentrations and was expressed as percentage of inaccuracy. In some situations, 
accuracy can be expressed as systematic error, representing also the recovery of each drug/assay. The parameter can be estimated by the value of the mean back-calculated concentrations divided by theoretical concentrations, expressed as percentage. The intra-day accuracy was evaluated by analysis of three replicates of the high (90.0 $\mu \mathrm{g} \mathrm{mL}-1)$, medium $\left(50.0 \mu \mathrm{g} \mathrm{mL}^{-1}\right)$ and low $\left(1.2 \mu \mathrm{g} \mathrm{mL} \mathrm{m}^{-1}\right)$ concentrations. The inter-day accuracy was determined by the analysis of three replicates of the high, medium and low concentrations of fluconazole on three different days.

Absolute recovery of fluconazole drugs from plasma was estimated by the peak area integrated for the drug in plasma versus the peak area integrated for the drug after direct injection of the same nominal drug concentration, expressed as a percentage. The efficiency of relative recovery was estimated by the peak area ratio integrated for each drug in plasma as compared to that of its internal standard.

\section{Specificity}

The specificity of an analytical method is its ability to measure accurately an analyte in the presence of endogenous compounds. The specificity was evaluated by the analysis of drug-free plasma samples (normal, hemolyzed, lipemic and icteric biological samples). The retention times of endogenous compounds were compared with those obtained for both fluconazole and the internal standard in the purified plasma extract.

\section{Limit of Detection and Limit of Quantification}

The limits of detection (LOD) and of quantification (LOQ) were determined based on the analysis of nine replicates. The LOQ was defined as the lowest plasma drug concentration on the calibration daily curve that could be determined with an accuracy of $80-120 \%$ and with a precision lower than $20 \%$. The LOD was defined as 0.5 times the limit of quantification. In addition, the LOD has a peak signal-to-noise ratio equivalent to $3: 1$, while the LOQ shows a ratio of $6: 1$.

\section{Stability study}

Study of short-term stability was performed at room temperature by several repetitions of a sequence of injections over $72 \mathrm{~h}$. The study was done by testing a sequence of micro vials on the rack of the auto sampler containing plasma extracts in four different concentrations $(2.2,20.0,50.0$ and $90.0 \mu \mathrm{g} \mathrm{mL}^{-1}$ ) determined on the basis of the daily curve.

Spiked blank plasma was analyzed by HPLC after the clean-up of the plasma samples after three freeze/thaw cycles.
The same sequence as detailed above was performed using four different concentrations $(2.2,20.0,50.0$ and $90.0 \mu \mathrm{g} \mathrm{mL}$ $\left.{ }^{1}\right)$ and analyzed in triplicate during three consecutive periods. Data were expressed as a percentage of the systematic error. The acceptance criterion for all concentrations studied was adopted at less than $10 \%$ variation.

\section{Robustness}

The robustness of the method was determined by using two different columns with small changes in the proportion of acetonitrile in the mobile phase. The study was developed using two different concentrations (3 replicates each). Data were expressed by systematic error, as a percentage.

\section{Therapeutic Drug Monitoring for dose adjustment}

The study was designed for drug plasma monitoring of fluconazole in burn patients with fungal infection plus sepsis. The six patients included in the study had the following characteristics: age: $44 \pm 15 \mathrm{yrs}$, body weight: $72.0 \pm 15.5$ $\mathrm{kg}$, total burned body surface area: $32.4 \pm 25.0 \%$ (TBSA $\%$, patient \#1: 70\%, \#2: 18\%, \#3: 10\%, \#4: 53\%, \#5: 8\%, \#6: $36 \%$ ). Either the patient or the legally responsible person was informed in detail about the procedures to be performed during the treatment, and written consent was acquired. The protocol was approved by the ethics committee of the hospital Clinical Hospital, Medical School, University of Sao Paulo, Brazil (HC FMUSP). A sequential allocation number was assigned for the identification of patients; data were described anonymously in accordance with ethical guidelines.

Antimicrobial therapy for the control of the sepsis caused by MRSA was an empirically dosed regimen of vancomycin ( $2 \mathrm{~g} /$ day, 1 hour infusion). Once the opportunistic fungal infection was also documented, the Hospital Committee of Infection recommended the inclusion of fluconazole $(200 \mathrm{mg}$ twice daily, $0.25 \mathrm{~h}$ infusion) in the therapy.

Fluconazole plasma monitoring was performed in different periods for each patient. Blood samples $(1 \mathrm{~mL})$ were collected at the trough from the arterial catheter. Each blood sample was transferred to tubes (BD, Sao Paulo, Brazil) containing sodium EDTA, and the plasma was separated by centrifugation at $3000 \mathrm{rpm}$ for $30 \mathrm{~min}$ and stored at $-20^{\circ} \mathrm{C}$ until analysis.

\section{RESULTS}

\section{Experimental}

The validation parameters for the quantification of fluconazole in the biological samples are shown in 
Table 1 . The specificity of the analytical method for the determination of fluconazole in biological samples was evaluated. Once endogenous compounds had been eluted over the first minute, no interference with the analysis was observed under the analytical conditions described above. Typical chromatograms of a blank plasma and spiked plasma are shown in Figure 1. The retention times were 9.3 and 13.3 minutes for fluconazole and carbamazepine (IS), respectively. Peaks were monitored at $210 \mathrm{~nm}$, and the total time required for each chromatographic run was 15 minutes to guarantee high selectivity and specificity.

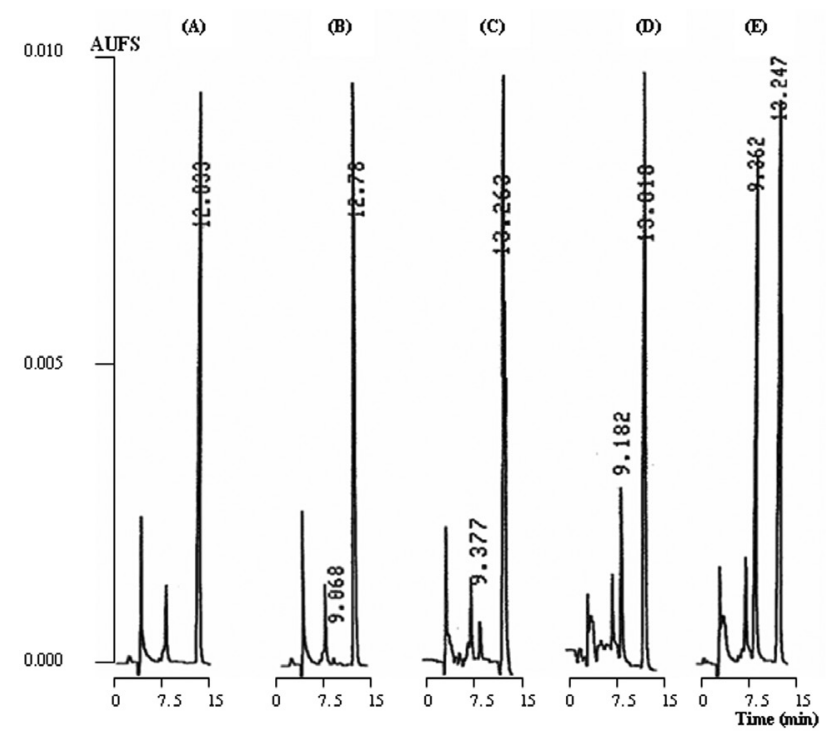

Figure 1 - Chromatographic profile of fluconazole in plasma. Chromatograms: (A) Blank plasma. (B) Spiked blank plasma extracts Lower limit of detection $\left(0.4 \mu \mathrm{g} \mathrm{mL}^{-1}\right)$; (C) Low standard $\left(2.2 \mu \mathrm{g} \mathrm{mL}^{-1}\right)$ and (E) Medium standard $\left(25.0 \mu \mathrm{g} \mathrm{mL}^{-1}\right)$. (D) Plasma extract of Patient \#3 $\left(15.0 \mu \mathrm{g} \mathrm{mL} \mathrm{mL}^{-1}\right)$. Retention times: $9.3 \mathrm{~min}$. (fluconazole) and $13.2 \mathrm{~min}$ (carbamazepine, internal standard).

The analytical method exhibits excellent linearity, based on good recovery, and acceptable accuracy and precision (Table 1). Data for the linearity studies were expressed by the intercept and also the slope of the linear function. The mean, standard error of the mean (SEM) and the linear determination coefficient $\left(r^{2}\right)$ are: intercept 0.0146 (SEM: 0.0183), slope 0.0273 (SEM: 0.0004) and $r^{2}: 0.998$ over 0.4$100.0 \mu \mathrm{g} \mathrm{mL}^{-1}$. The detection limit was $0.2 \mu \mathrm{g} \mathrm{mL}^{-1}$, and the quantification limit was $0.4 \mu \mathrm{g} \mathrm{mL^{-1 }}$ based on the analysis of $0.2 \mathrm{~mL}$ plasma in 10 replicates.

The method showed good sensitivity, linearity and stability, with acceptable accuracy and precision (Table 1). In addition, small variations in the proportion of acetonitrile in the mobile phase showed acceptable precision and systematic error (Table 1). It should be emphasized that no robustness was investigated in the methods previously reported.

Analysis of the short-term stability of fluconazole (time and conditions of analysis) indicated no degradation of the drug in the plasma extract within a period up to $72 \mathrm{~h}$ while in vials on a tray of the chromatographic system. The short-term stability of fluconazole in plasma on the bench showed good precision $(4.8 \%)$ and systematic error $(-1.8 \%)$. Thaw cycles showed good stability of the drug in biological samples after three consecutive freeze/thaw cycles (Table 1).

\section{Therapeutic Drug Monitoring}

The validated bioanalytical method was applied to fluconazole plasma monitoring in six burn patients. Trough bloods drawn were obtained in different periods for each patient. Figure 2 shows for the six patients investigated. fluconazole plasma concentrations versus time during the follow-up period.

Table 1 - Mean confidence limits of analytical method of fluconazole in plasma.

\begin{tabular}{lcc}
\hline Parameter & Unit & Confidence Limits \\
\hline $\begin{array}{l}\text { Linearity (triplicate) } \\
\text { Linear regression }(\mathrm{n}=3 \text { curves })\end{array}$ & $\mu \mathrm{g} \mathrm{mL}{ }^{-1}$ & $\begin{array}{c}0.4-100.0 \\
\mathrm{r}^{2}=0.998\end{array}$ \\
LOD $\left(0.2 \mu \mathrm{gL}^{-1}\right)(\mathrm{n}=10)$ & $\mathrm{CV} \%$ & 2.6 \\
LOQ $\left(0.4 \mu \mathrm{gL}^{-1}\right)(\mathrm{n}=10)$ & $\mathrm{CV} \%$ & 3.2 \\
Absolute recovery $(\mathrm{n}=24)$ & $\%$ & 98.6 \\
Relative recovery $(\mathrm{n}=24)$ & $\%$ & 104.2 \\
Precision/within-day $(\mathrm{n}=9)$ & $\mathrm{CV} \%$ & \\
$90.0 \mu \mathrm{g} \mathrm{mL}{ }^{-1}$ & & 1.44 \\
$50.0 \mu \mathrm{g} \mathrm{mL}$ & & 4.60 \\
$1.2 \mu \mathrm{g} \mathrm{mL}$ & & 3.21
\end{tabular}

Precision/between-days $(\mathrm{n}=18)$

$\mathrm{CV} \%$

$90.0 \mu \mathrm{g} \mathrm{mL}^{-1}$

0.99

$50.0 \mu \mathrm{g} \mathrm{mL}^{-1}$

$1.2 \mu \mathrm{g} \mathrm{mL} \mathrm{m}^{-1}$

Accuracy/within-day $(\mathrm{n}=9)$

$\%($ mean+/- SD)

$90.0 \mu \mathrm{g} \mathrm{mL} L^{-1}$

$98.1-100.1$

$50.0 \mu \mathrm{g} \mathrm{mL}^{-1}$

$92.6-95.8$

$1.2 \mu \mathrm{g} \mathrm{mL}^{-1}$

$101.3-107.5$

Accuracy/between-days $(\mathrm{n}=18) \quad \%($ mean+/- SD)

$90.0 \mu \mathrm{g} \mathrm{mL} \mathrm{H}^{-1}$

$97.6-100.7$

$50.0 \mu \mathrm{g} \mathrm{mL}^{-1}$

$89.3-99.1$

$1.2 \mu \mathrm{g} \mathrm{mL}$

$103.7-105.1$

Stability /thawing cycles

SE\%

Cycle 1 $(n=12)$

0.06

Cycle 2(n=12)

1.65

Cycle 3(n=12)

1.22

Abbreviations: coefficient of variation (CV\%), standard deviation of mean (SD), systematic error (SE\%), higher and lower limits (mean+/-SD) for accuracy and precision. Symbol: $\mathrm{r}^{2}$ : coefficient of determination. 


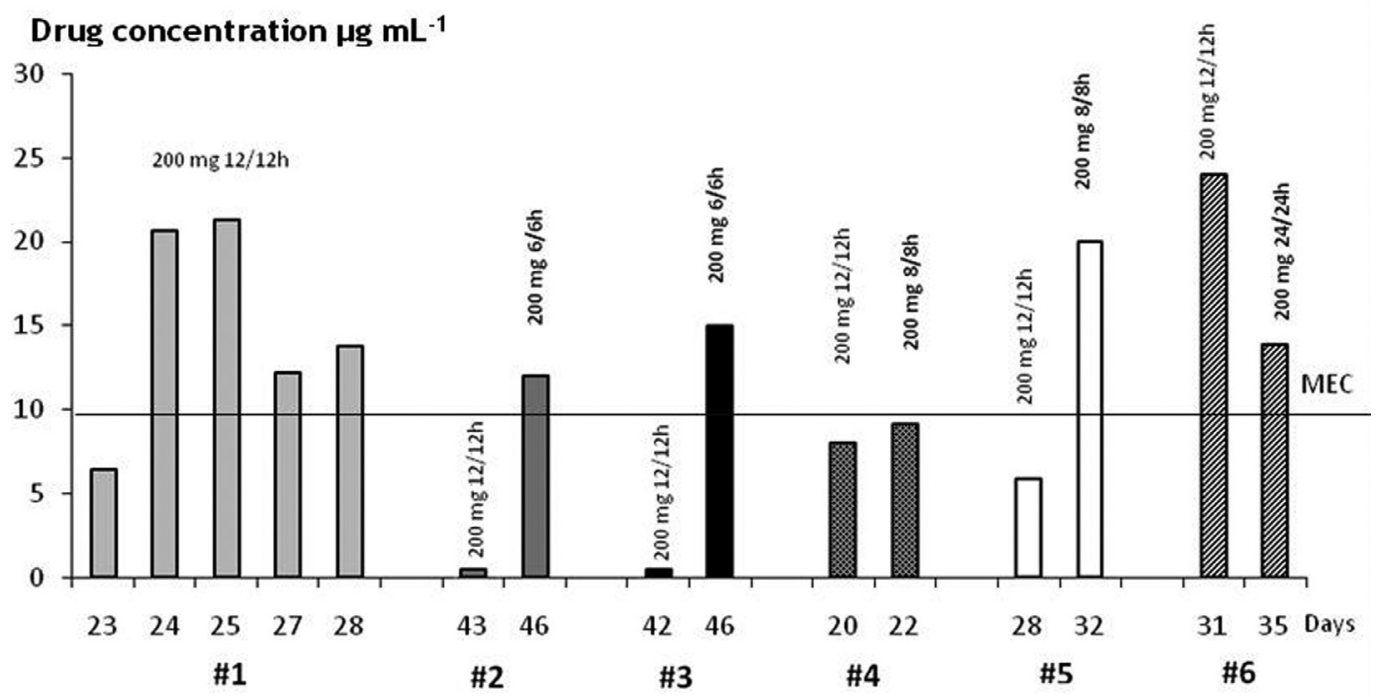

Figure 2 - Antimicrobial therapy was started at an empirical dose regimen (fluconazole $200 \mathrm{mg}$ twice daily, fast infusion) and was altered based on therapeutic drug monitoring of six burn patients with fungal infection. Trough plasma levels were obtained at different days after the accident. Abbreviation: minimum effective concentration (MEC $>10 \mu \mathrm{g} / \mathrm{mL}$ ).

An increase in the empirical daily dose was required for most patients to maintain clinical efficacy related (defined as a trough higher than the minimum effective concentration of $10 \mu \mathrm{g} / \mathrm{mL}$ ). There was no accumulation after multiple infusions of the empirical dose regimen in patients \#2 and $\# 3$, as seen by the trough lower than $1 \mu \mathrm{g} / \mathrm{mL}$. Thus, their daily dose was increased 2 -fold, from $400 \mathrm{mg} /$ day (200 mg every $12 \mathrm{hrs}$ ) to $800 \mathrm{mg} /$ day ( $200 \mathrm{mg}$ every $6 \mathrm{hrs}$ ) to reach a trough higher than $10 \mu \mathrm{g} / \mathrm{mL}$. The daily dose was increased 1.5 times for patient \#5 because a trough equivalent to $5 \mu \mathrm{g} /$ $\mathrm{mL}$ was obtained after the empirical daily dose. The daily dose was increased to $600 \mathrm{mg}$ daily ( $200 \mathrm{mg}$ every $8 \mathrm{hrs}$ ) for patient \#4, but the minimum effective concentration at the trough was not reached. ${ }^{3}$

For patient \#6, a $50 \%$ reduction in the daily dose (from $400 \mathrm{mg}$ /daily to $200 \mathrm{mg}$ day) was required, as a trough fluconazole plasma level higher than $20 \mu \mathrm{g} / \mathrm{mL}$ was obtained after the empirical dose regimen. After the empirical dose regimen, patient \#1 showed trough plasma levels higher than $10 \mu \mathrm{g} / \mathrm{mL}$ in four consecutive periods. The high variability in fluconazole plasma levels obtained on days 24, 25, 27 and 28 are probably due to changes in drug kinetics reported generally for antimicrobials and specifically for fluconazole in burn patients. ${ }^{18-20}$

Considering the trough plasma levels for all patients monitored in the present study (Figure 2), dose adjustment was required to reach clinical efficacy in most patients due to failure of the empirical dose regimen (Figure 3).

\section{DISCUSSION}

Analytical methods reported for the determination of

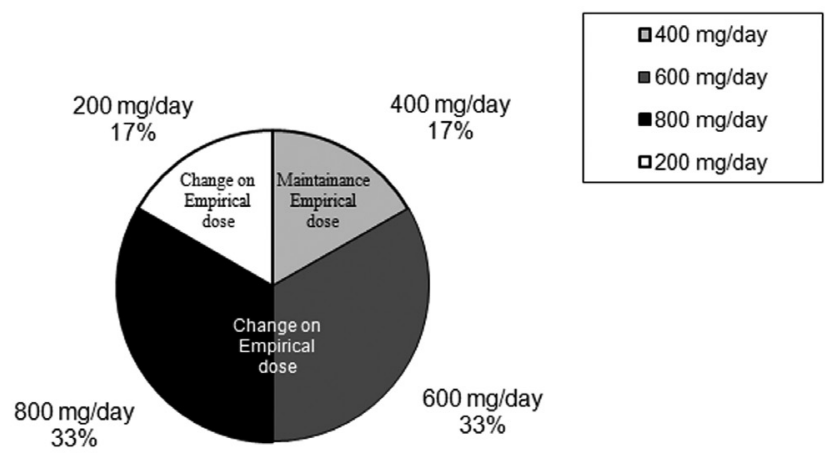

Figure 3 - Dose adjustment of fluconazole to reach clinical efficacy was required in $5 / 6$ burn patients with fungal infection. Antifungal therapy was started at the empirical dose regimen (200 mg twice daily, fast infusion). Data are expressed as the percentage of patients that required changes to the empirical dose regimen to reach clinical efficacy.

fluconazole in plasma ${ }^{9,12-16}$, serum, ${ }^{10,11,14}$ cerebral spinal fluid ${ }^{14}$ and saliva ${ }^{13}$ have employed LC-UV after several purification procedures. A direct injection into the chromatographic system of small volumes of diluted plasma or extracts obtained from plasma protein precipitation showed serious problems related to specificity and selectivity. A large number of runs were required, and the reduction in the lifetime of the analytical column and leakage as a consequence of the blockade of the injector must be considered. ${ }^{10-12}$

Therapeutic drug monitoring of antimicrobial agents contributes considerably to dose adjustments and drug efficacy in burn patients. Problems such as blood sample collection in limited-access patients, and problems related to volume of blood drawn and the frequency of sampling must be solved. In addition, it is necessary that the analytical method have a high sensitivity for drug plasma 
measurement. As described in the present study, only 0.2 $\mathrm{mL}$ of plasma was necessary for drug analysis. Analytical methods that present low sensitivity require higher plasma volumes ( 0.5 to $1.0 \mathrm{~mL}$ ) and thus may be considered inadequate for fluconazole plasma measurements., ${ }^{9,13,14}$

For the plasma purification done prior to the chromatographic measurement, solid-phase extraction (SPE) is a good option with high selectivity and sensitivity. Next best is the liquid-liquid extraction procedure, which is preferable due to its low cost compared to $\mathrm{SPE}^{9,13,14,16}$. Higher recovery of fluconazole was obtained by a liquid-liquid single extraction in an alkaline medium than in data reported previously. ${ }^{13-15}$ Both of the above procedures are favorable to plasma protein precipitation using methanol or acetonitrile.

In the present study, the analytical method used in the determination of fluconazole in plasma by HPLC-UV is quite simple, rapid and low in cost. Considering the selectivity, specificity, and sensitivity of the analytical method, the choice of the wavelength of the ultraviolet detector is important to guarantee the detection of low plasma levels accurately. A wavelength of $210 \mathrm{~nm}$ is usually applied for the detection of plasmatic fluconazole analyzed by LC. ${ }^{11-13,16}$ It has been suggested that 260 $\mathrm{nm}$ might be a more convenient wavelength because nonspecific substances detected at $210 \mathrm{~nm}$ could be coeluted and consequently interfere with the area of peak integrated for each analyte..$^{9,10,14-16}$ Nevertheless, in the present method, no peak of any substance was co-eluted with fluconazole or its internal standard; the specificity and selectivity of the method was good, although a peak of an endogenous compound was recorded in the chromatogram at approximately 7.5 minutes of retention time.

Concerning the chromatographic conditions for fluconazole plasma measurements, the separation was performed in a reverse-phase column and with a mixture of purified water plus acetonitrile as the mobile phase at a $0.5 \mathrm{~mL} \mathrm{~min} \mathrm{~m}^{-1}$ flow rate. This method was superior to the analytical procedures reported previously. ${ }^{9-16}$

Compared to data reported previously, the linearity obtained in the present study showed a greater detectable range for fluconazole plasma concentrations., ${ }^{9,10,12,14-16}$ Data obtained in the present study were comparable to the results described by Koks et al., in spite of the higher plasma volumes required ${ }^{13}$.

\section{Therapeutic Drug Monitoring (TDM)}

The literature recommends ten times the minimum

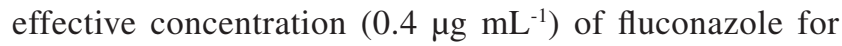
antifungal prophylaxis. ${ }^{4,6,21-24,26}$ However, it was reported that for effective pharmacotherapy of candidiasis, the fluconazole

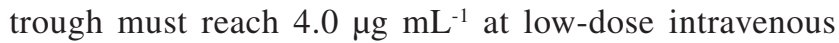
therapy of $100 \mathrm{mg}$ a day. ${ }^{6,22,23}$ The length of the infusion matters; if the drug is infused over 2 hours instead of 10 minutes, lower troughs $\left(2.2 \mu \mathrm{g} \mathrm{mL}^{-1}\right)$ can be expected. ${ }^{24}$

In the present study, fluconazole plasma monitoring was applied to investigate six hospitalized burn patients (8-70\% TBSA) from the Intensive Care Burn Unit. The patients were receiving an empirical dose regimen of $200 \mathrm{mg}$ every 12 hours (400 mg daily) for systemic fungal infection. Some were dose-adjusted up to $800 \mathrm{mg}$ a day on the basis of the drug plasma monitoring. Dose adjustments of fluconazole to reach clinical efficacy were required in 5/6 burn patients with fungal infection. The dose regimen remained unchanged only for patient \#1. The dose was increased up to $800 \mathrm{mg}$ daily for patients \#2, \#3, \#4 and \#5, but the dose was reduced to $200 \mathrm{mg}$ daily for patient \#6 due to moderate renal insufficiency (creatinine clearance, $40 \mathrm{~mL} / \mathrm{min}$ ).

The fluconazole plasma troughs reported previously ranged from 20 up to $50 \mu \mathrm{g} \mathrm{mL}^{-1}{ }^{25}$ or up to $70 \mu \mathrm{g} \mathrm{mL}^{-1}$ for high-dose therapy $\left(800 \mathrm{mg} \mathrm{day}^{-1}\right){ }^{26}$ Additionally, because the diffusion of the drug through the blood-brain barrier is rapid, drug levels in the cerebral spinal fluid (CSF) were about $70 \%$ of fluconazole plasma levels..$^{22,23,26}$ Menichetti et al. reported that at high-dose therapy, the drug level in CSF is equivalent to $36 \pm 21 \mu \mathrm{g} \mathrm{mL} \mathrm{m}^{-1}$, and a plasma/CSF ratio of approximately 1.0 was shown. ${ }^{26}$ On the other hand, the fluconazole trough ranged from $4.6 \mu \mathrm{g} \mathrm{mL} \mathrm{mL}^{-1}$ to $9.0 \mu \mathrm{g} \mathrm{mL}^{-1}$ at low-dose therapy (200 - $400 \mathrm{mg}$ daily), as reported by Cousin et al. ${ }^{4}$

Fluconazole trough plasma levels during the empirical dose regimen (200 $\mathrm{mg}$ twice daily, or $400 \mathrm{mg}$ a day) in the first period of drug therapy were used to determine the dose adjustment required to reach clinical efficacy in burn patients investigated. The patients had a large variability in the TBSA registered: \#1 (TBSA: 70\%), \#2 (18\%), \#3 (10\%), \#4 (53\%), \#5 $(8 \%)$ and \#6 (36\%). Data obtained in the present study are in agreement with the results reported previously by Rayatt et al. based on changes in drug plasma levels as a consequence of kinetic changes in burn patients receiving the empirical dose (400 mg once daily) for the control of fungal infection. ${ }^{27}$ Controversially, Boucher et al. reported no change in the pharmacokinetics of severe burn patients receiving fluconazole (2-hour infusion, $400 \mathrm{mg}$ every 24 hours) on the basis of variability of burn area. ${ }^{20}$

\section{CONCLUSION}

The method validated is simple, rapid, sensitive and selective, requires a low plasma volume and has acceptable confidence limits. It is relatively low-cost, making the procedure economically viable and appropriate for management of burn patients. The trough can be altered 
in burn patients, probably as a consequence of important changes in their pharmacokinetics. This may explain changes in drug accumulation over time. Therapeutic drug monitoring will be useful in long-term antifungal therapy of burn patients to maintain clinical efficacy. High variability in plasma levels in these patients over time can be expected.

\section{REFERENCES}

1. Goa KL, Barredell LB. Fluconazole. An update of its pharmacodynamic and pharmacokinetic properties and therapeutic use in major superficial and systemic mycoses in immunocompromised patients. Drugs. 1995;50:658-90.

2. Henderson HM, Chapman SW. Infections due to Fungi, Actinomyces and Nocardia. In: Betts RF, Chapman SW, Penn RL. Editors. Reese and Betts' a practical Approach to Infectious Diseases. ${ }^{\text {th }}$ ed. Philadelphia: Lippincott Williams \& Wilkins; 2003;628-30.

3. Debruyne D, Ryckelynck JP. Clinical Pharmacokinetics of fluconazole. Clin Pharmacokinet. 1993;24:10-27

4. Cousin L, Berre M, Launay-Vacher V, Izzedine H, Deray G. Dosing guidelines for fluconazole in patients with renal failure. Nephrol Dial Transplant 2003;18:2227-31.

5. Fernandez ACM, Pimentel TT, Martinez MG, Gonzalez MM. Determination of the minimun inhibitory concentration of fluconazole against Cryptococcus neoformans. Ver. Cubana Med Trop. 1999;51:557.

6. Gallagher JC, Lee KB. Program to restrict use of i.v. fluconazole. Am J Health Syst Pharm. 2004;61:1695-8.

7. Jaehde L, Sorgel F. Clinical pharmacokinetics in patients with burns. Clin Pharmacokinet. 2000;29:15-28.

8. Fraser VJ, Jones M, Dunkel J, Strofer S, Medoff G, Dunagan WC. Candidemia in tertiary care hospital: epidemiology, risk factors, and predictors of mortality. Clin Infect Dis. 1992;15:414-21.

9. Wattananat T, Wiyada A. Validated HPLC method for the determination of fluconazole in human plasma. Biomed Chromatogr. 2006;20:1-3.

10. Egle H, Trittler R, Kûmmerer K. A new, rapid, fully automated method for determination of fluconazole in serum by column-switching liquid chromatography. Ther Drug Monit. 2004;26:425-31.

11. Ng TKC, Chan RCY, Adeyemi-Doro FAB, Cheung SW, Cheng AFB. Rapid high performance liquid chromatographic assay for antifungal agents in human sera. J Antimicrob Chemother. 1996;37:465-72.

12. Cociglio M, Brandissou S, Alric R, Bressolle F. High-performance liquid chromatographic determination of fluconazole in plasma. J Chromatogr Biomed Appl. 1996;686:11-7.

13. Koks CHW, Rosing H, Meenhorst PL, Bult A, Beijnen J. H. Highperformance liquid chromatographic determination of the antifungal drug fluconazole in plasma and saliva of human immunodeficiency virus-infected patients. J Chromatogr Biomed Appl. 1994;663:435-51.

14. Wallace JE, Harris SC, Gallegos J, Foulds G, Chen TJ, Rinaldi MG. Assay of fluconazole by high-performance liquid chromatography with a mixed-phase column. Antimicrob Agents Chemother. 1992;36:603-6.
15. Flores-Murrieta FJ, Granados-Soto V, Hong E. Simple and rapid method for determination of fluconazole in human plasma samples by high performance liquid chromatography. J Liq. Chromatogr. 1994;17:380311.

16. Inagaki K, Takagi J, Lor E, Okamoto MP, Gill MA. Determination of fluconazole in human serum by solid-phase extraction and reversedphase high-performance liquid chromatography. Ther Drug Monit. 1992;14:306-11.

17. FDA Home page. Guidance for Industry: Bioanalytical Method Validation, http://www.fda.gov/cder/guidance/4252fnl.htm, 2008.

18. Weinbren MJ, Pharmacokinetics of antibiotics in burn patients. J Antimicrob Chemother. 1999;44:319-27.

19. Blanchet B, Jullien V, Vinsonneau C, Tod M. Influence of burns in pharmacokinetics of drugs used in the care of burn patients. Clin pharmacokinet. 2008;47:635-54.

20. Boucher AB, King SR, Wandschneider HL, Hickerson WL, Hanes SD, Herring VL, et al. Fluconazole pharmacokinetics in Burn Patients. Antimicrob Agents Chemother. 1998;930-3.

21. Sia-Cheing L, Chang-Phone F, Jen-Seng H, Chin-Jen T, Kuo-Su C, Huang-Yang C, et al. Clinical correlates of antifungical macrodilution susceptibility test results for non-AIDS patients with severe candida infections treated with fluconazole. Antimicrob Agents Chemother. 2000;44:2715-8.

22. Foulds G, Brennan DR, Wajszczuk C, Cattanzaaro A, Gaarg DC, Knopf W, et al. Fluconazole penetration into cerebrospinal fluid in humans. J Clin Pharmacol. 1988; 28:363-6.

23. Tucker R, Williams PL, Araathoon EG, Levine BE, Haartstein AI, Hanson LH, et al. Pharmacokinetics of fluconazole in cerebrospinal fluid and serum in human coccidioidal meningitis. Antimicrob Agents Chemother. 1988;32:369-73

24. DeMuria D, Forrest A, Rich J, Scavone JM, Cohen LG, Kazanjian PH Pharmacokinetics and bioavailability of fluconazole in patients with AIDS. Antimicrob Agents Chemother. 1993;37:2187-92.

25. Haubrich KH, Haghighat D, Bozzette AS, Tilles J, McDutchan JA. Highdose fluconazole for treatment of cryptococcal disease in patients with human immunodeficiency virus infection. The California collaborative treatment group. J Infect Dis. 1994;170:238-42.

26. Menichetti F, Fiorio M, Tosti A, Gatti G, Pasticci MB, Miletich F, et al. High-dose fluconazole therapy for cryptococcal meningitis in patients with AIDS. Clin Infect Dis. 1996;22:838-40.

27. Rayatt S, Weimbre M, Clarke J. Fluconazole use in burns patients. Burns 2000;26: 109-10. 